\title{
Principle of Organization for Laboratory Stand of the Electric Drive with a Real Regulatory System No Time Scaling
}

\author{
Andrii Pirozhenko ${ }^{1}$, Yevhenii Modlo ${ }^{1}$, Ruslan Shaida, Viktor Batarieiev ${ }^{1}$, Mykola Zhukov ${ }^{1}$, and Mykhailo Drukker ${ }^{1}$ \\ ${ }^{1}$ State university of economics and technology, 50006, Kryvyi Rih, Ukraine
}

\begin{abstract}
The existing practical training of specialists in the field of the electric drive is recognized as insufficient, not allowing them to conduct independently a complex of adjustment works or works on elimination of refusals. All known virtual methods of research of electric drives are scaled in time therefore at the trained skills on use of the measuring and registering devices during the work on real installation don't develop, and also skills on work with real knots of control systems for control of the set drive modes. We propose a stand consisting of a real system of regulation and the model of the power drive to work without time scale, thus significantly closer to the actual laboratory setting drive. The structure of the laboratory stand on the basis of the engine of a direct current of independent excitement with the reversible thyristor converter is in details considered. It is proved that an optimal algorithm for the simulation of three-phase bridge converter operating at anchor chain is an algorithm which rooms include a thyristor and of the remaining thyristors allows you to choose the design scheme and carry out the integration of equations describing electric processes in the circuit detect a change in state of the thyristors and the transition to other design scheme. Given the discrete model and considered design scheme of three-phase bridge Converter in a normal mode switching thyristors and emergency mode, if false turn on of the thyristor during commutation. Mathematical model of the device - the solution of differential equations by numerical integration of the Runge-Kutta. Proposed hardware mathematical model based on the family of microcomputer ARM CortexTM fourth generation.
\end{abstract}

\section{Introduction}

The problem and its connection with scientific and practical tasks. Training of specialists in the field of the electric drive in higher educational institutions was generally reduced the last years to theoretical part. Practical preparation was limited to performance of standard laboratory works, thus owing to known circumstances (the high cost of stands, restrictions connected with safety measures, restrictions on drive power, etc.) students independently can't conduct a complex of adjustment works or works on elimination of refusals. Besides, practical training of specialists has to provide variety of tasks, for example, ability to carry out adjustment of control systems for drives with engines of various power, various character of loading, etc. Thus it is necessary to provide the minimum capital and operational expenditure connected with creation of the laboratory stand.

\section{Literature Review}

The analysis of researches and publications. Now virtual methods of research of electric drives which provide variety of tasks, rather low capital expenditure are widely used and don't demand special events for safety of performance of laboratory works [1-6]. But, as known methods of research of electric drives are scaled in time, at the trained skills on use of the measuring and registering devices during the work on real installation, and also skills on work with real knots of control systems for control of the set operating modes of the drive don't develop. Thus, the existing approaches in creation of the laboratory stand for training of specialists in the field of the electric drive using the modeling installations working in time scale won't allow to solve objectives.

\section{Statement of the problem}

The creation of the laboratory stand for training in setting up and Troubleshooting control systems electric drive, consisting of a real regulatory system and model of the power part of the actuator operating without time scale.

\section{Material statement and results}

If we consider the laboratory plant consisting of a real control system and model of the power unit (Converter installations and motor) operating without time scale, we get a significant approximation of the laboratory setup to a real drive. Structural scheme of such installation is shown in Fig.1. 


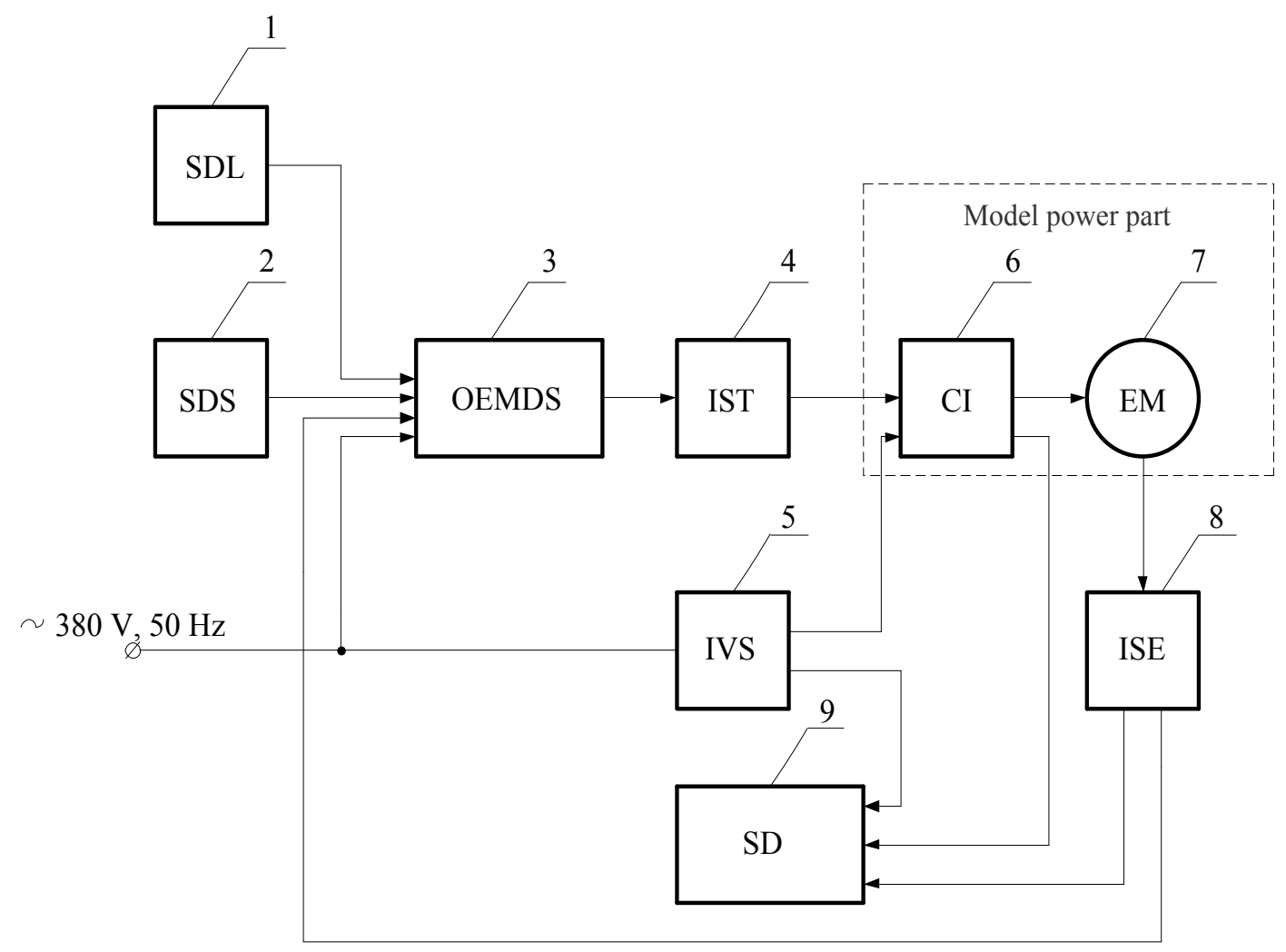

Fig. 1. Laboratory setting consisting of real control system and model of power part.

On fig. 1 shown: 1 - specifies the device load on the motor shaft (SDL), 2 - specifies the device speed of rotation of the motor shaft (shaft position)(SDS), 3 an operating electric motor drive system (OEMDS), 4 - an interface of transformation of output signals of OEMDS into the discrete input signals of microcontroller (IST), 5- an interface of transformation of three-phase supply voltage analog input signals of the microcontroller (IVS), 6 - a model of converter installation (CI), 7 - a model of electric motor (EM), 8 - digital signal converter EM in the relevant voltages and currents for organization of feedbacks of OEMDS and connect measuring devices (ISE), 9 - SD are devices for measuring of current (ammeters), voltage (voltmeters) or terminals for connecting of supervision devices.

As the article has limited size it was only considered the matter subject to developing the laboratory stand for educating the methods of tuning and repair of electric motor drive control systems based on separately excited direct-current motor with a reversible thyristor converter. In this case SDL and SDS are potentiometer, synchrotransmitter and the like reference-input elements of the set value of speed (load moment), or programmable devices for determination of diagrams to speed, position and loading. OEMDS is, for example, the analog control system of ETAL ETU 200 , or the digital system "DC MASTER" by Siemens. The outputs of these and other control systems are impulse signals of turn-on of thyristors. That's why the ICT contains the elements of transformation of signal level and its galvanic isolation. CI is a model of reversible thyristor converter for the feed of motor armature and non-reversible converter for the feed of drive winding. EM is model of the electric motor of a direct current of independent excitement. All models should work in real time. ISE is a set of digital-toanalog converters of digit values of thyristors' currents and voltages, of electric motor windings and speed, of motor shaft position calculated by models, and also the converter of digital value of motor shaft position into pulse string similar to the signals of incremental encoder. IVC is a galvanic isolation with the voltage divider and quick-operating analog digital converters.

Model of the mechanical parts of the actuator advisable to execute on a separate microcontroller. On the speed (the provision of a shaft of the electric motor) and known mechanical characteristics of elements of the kinematic scheme, the loading moment on an engine shaft is defined, and its moment - on current of an anchor and a stream of excitement. The moment of the electric motor is the operating influence of model of mechanical part of the drive and the loading moment - revolting influence of model of electric part. This issue is well studied, and its implementation does not contain problems.

Electric part of model of electric motor is standard, without the account of reaction of anchor and at supposition, that the number of slots is infinitely large, i.e. the anchor chain of engine and chain of excitation is described linear differential equalization of the first order, taking into account nonlinear dependence anti E.M.F. engine from the current of excitation. The model of anchor chain of engine, as a rule, is combined with the model of transformer. 
Basic problem, arising up at creation of similar stands, it is the limited fast-acting of microcontroller for realization of model, working in real time. For the estimation of necessary fast-acting of microcontroller will consider the algorithm of work of models of transformers and engines of direct-current which is expedient for creation of the indicated stand. The models of electric drive of direct-current with a reversible thyristor transformer are known and widely used for planning of thyristor transformers [7,8] and for the virtual models of electric drive of direct-current. In first case they are a volume, because contain the models of semiconductor devices, in second case usually models simplified, as ignore the processes of commutation and the terms of disabling thyristor are unchecked.

In our case it is not necessary to consider transients in thyristor, it is sufficient to assume that:

the inclusion of the thyristor occurs instantly if the conditions of its inclusion (positive edge pulse on the control electrode of the thyristor and the positive voltage of the anode - cathode thyristor);

the inclusion of the thyristor occurs at a given, for this model of thyristor, the reverse current through it.

To obtain emergency modes of operation of the converter it is necessary to model the converter take into account switching processes when you enable (turn off) thyristor and contained a control voltage to the thyristors.

Two approaches are used when developing algorithms for simulation of three-phase bridge converters, working on the anchor chain of the engine:

the number of thyristor, which is fed with pulse on and the other thyristors (enabled/disabled) select a design scheme and executed the integration of the equations describing the electrical processes in the scheme, the following defines the moment of changing the state of the thyristor and switch to a different design scheme, and in the on state resistance of the thyristor is equal to zero, off - infinity;

calculated currents and voltages in all branches of the circuit, wherein the thyristor is replaced by a dipole whose parameters are changed depending on condition of the thyristor.

For example, if we consider the converter modes: a) normal mode rectification, b) the switching of the thyristors and c) emergency mode, if false turn on of the thyristor during commutation, we get three calculation schemes are shown in figure 2.

Sources of EMF in settlement schemes, the number of the controlled current to determine the moment of disconnection of the thyristors, the sign of the back EMF of the motor (zne), depend on the operating rooms and turn on the thyristors, as shown in table 1. The numbering of the thyristors in the table $\mathrm{K}=1 \ldots 6$ corresponds to the sequence of their inclusion in time, the thyristor 1 is installed in the cathode group of phase A. In the design schemes

$$
i=\left\{\begin{array}{c}
i=k \quad \text { if } \quad(1 \leq \mathrm{i}) \cap(i \leq 6) \\
i=k-6 \text { if } i>6
\end{array}\right.
$$

$i+2$ included the thyristor; $i+3,4,5$ - falsely included thyristors.

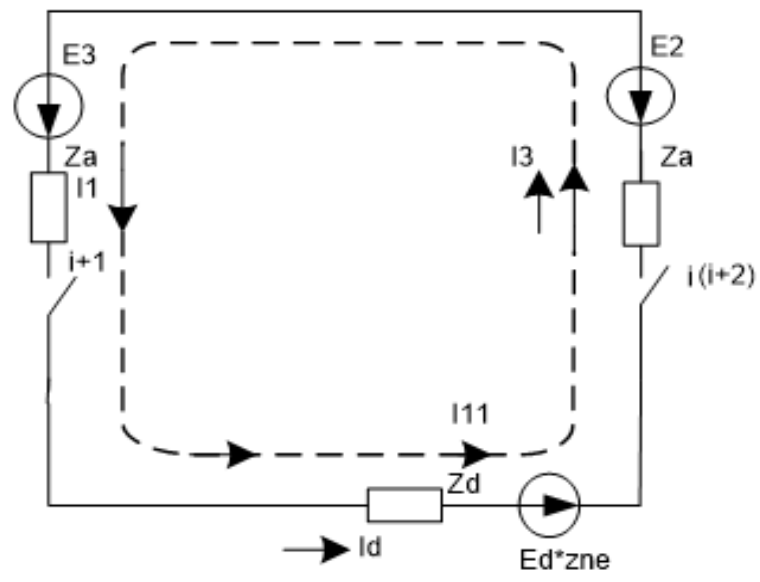

A)

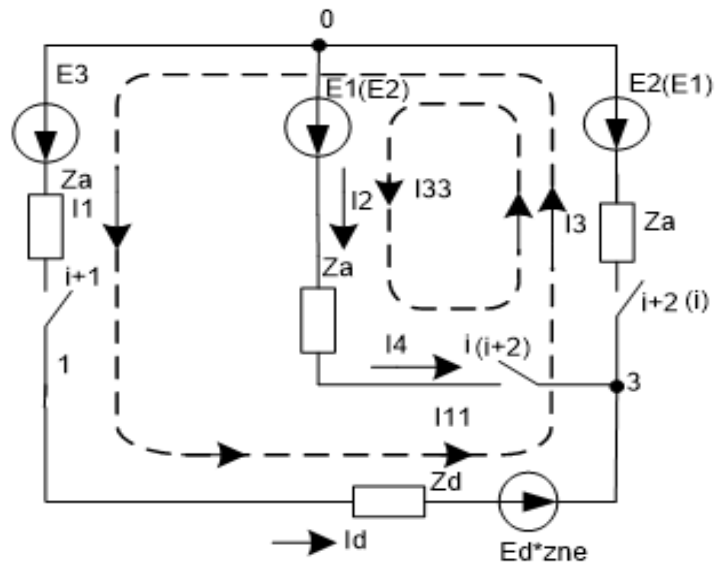

B)

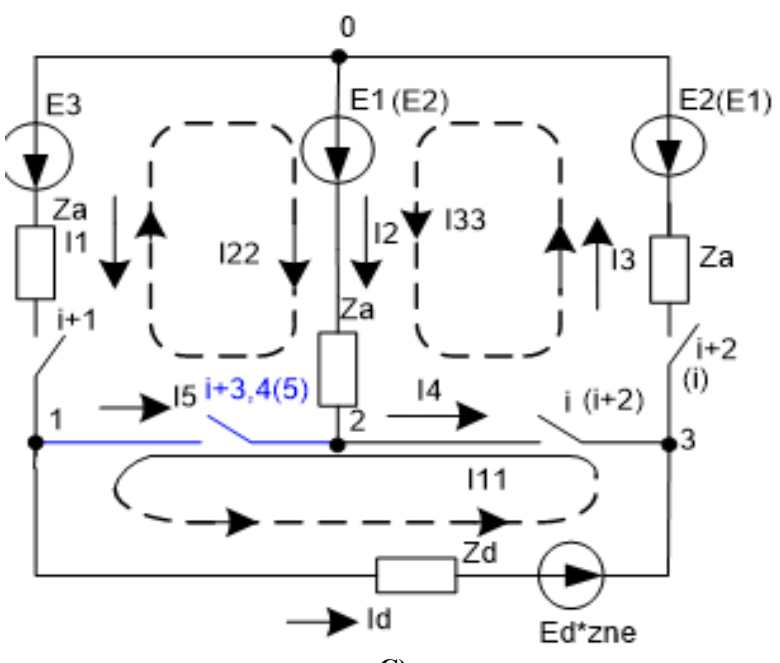

C)

Fig. 2. Calculation schemes/models of three-phase bridge converter 
Table 1. Characteristics of thyristors 3-phase bridge converter

\begin{tabular}{|c|c|c|c|c|c|c|c|c|c|}
\hline \multirow{2}{*}{$\begin{array}{l}\text { Commutation } \\
\text { in group }\end{array}$} & \multirow{2}{*}{$\begin{array}{l}\text { Working } \\
\text { thyristors }\end{array}$} & \multirow{2}{*}{$\begin{array}{l}\text { The } \\
\text { included } \\
\text { tiristors }\end{array}$} & \multicolumn{3}{|c|}{ Sources } & \multirow{2}{*}{$\mathrm{i}$} & \multirow{2}{*}{$\mathrm{i}+1$} & \multirow{2}{*}{$i+2$} & \multirow{2}{*}{$\begin{array}{c}\text { Sign } \\
\text { Ed } \\
\text { zne }\end{array}$} \\
\hline & & & E1 & E2 & E3 & & & & \\
\hline \multirow{3}{*}{$\begin{array}{l}\text { cathode } \\
\text { group }\end{array}$} & 1,2 & 3 & $\mathrm{Ua}$ & $\mathrm{Ub}$ & Uc & 1 & 2 & 3 & + \\
\hline & 3,4 & 5 & $\mathrm{Ub}$ & $\mathrm{Uc}$ & $\mathrm{Ua}$ & 3 & 4 & 5 & + \\
\hline & 5,6 & 1 & $\mathrm{Uc}$ & $\mathrm{Ua}$ & $\mathrm{Ub}$ & 5 & 6 & 1 & + \\
\hline \multirow{3}{*}{ anode group } & 6,1 & 2 & $\mathrm{Ub}$ & $\mathrm{Uc}$ & $\mathrm{Ua}$ & 6 & 1 & 2 & - \\
\hline & 2,3 & 4 & $\mathrm{Uc}$ & $\mathrm{Ua}$ & $\mathrm{Ub}$ & 4 & 3 & 4 & - \\
\hline & 4,5 & 6 & $\mathrm{Ua}$ & $\mathrm{Ub}$ & Uc & 2 & 5 & 6 & - \\
\hline
\end{tabular}

The order of switching of the thyristors is determined by a hardware-implemented control system of thyristor converter and electric drive in normal mode. Emergency operation of thyristor can forcibly be set by the program of management of model depending on an electric drive research problem. The program of model defines number of the settlement scheme then the subprogramme of the solution of the differential equations corresponding to this scheme joins.

The accuracy of the solution is determined step integration of the equations. Thus, the main impact on errors of a method of modelling will be had by time of the solution of the differential equations.

The simplified diagram of the algorithm of the model showing on the figure 3 .

Most of the time the calculations are carried out according to the scheme of figure $2 \mathrm{a}$, in the period of commutation calculations are carried out according to the scheme of figure $2 b$, and the time of switching for three-phase bridge converter is about $34 \%$ of the duration of the conversion interval.

Despite the last circumstance, it is necessary to choose an integration step proceeding from need of the solution of two differential equations which are worked out on a method of planimetric currents for electric part of the drive, the differential equation for mechanical part of the drive and definition on in advance set logical equation of values of EMF in the equations for an anchor chain of the engine.

The coefficients of the equations is a positive number, constant for the actuator, to define them in part of the preparations for the decision. When using a micro-computer that computes in the format with a fixed decimal point, are calculated according to the magnitude of currents and voltages. For modeling the converter with the engine in the second method we will use methods of calculation of electric circuits on the PC, was considered in [9]. For the calculation method of nodal potentials the discrete circuit model ra-La is given on the figure $4 \mathrm{a}$, and the circuit $\mathrm{rd}-\mathrm{Ld}$ on the figure $4 \mathrm{~b}$, the discrete model of the converter circuit non-reversing engine shown on the figure $4 \mathrm{c}$. You can see on the figure that ga - anode circuit of the thyristors, gd - anchor chain of the engine, the gt is a two - terminal thyristor of substitution (in our case the conductivity).

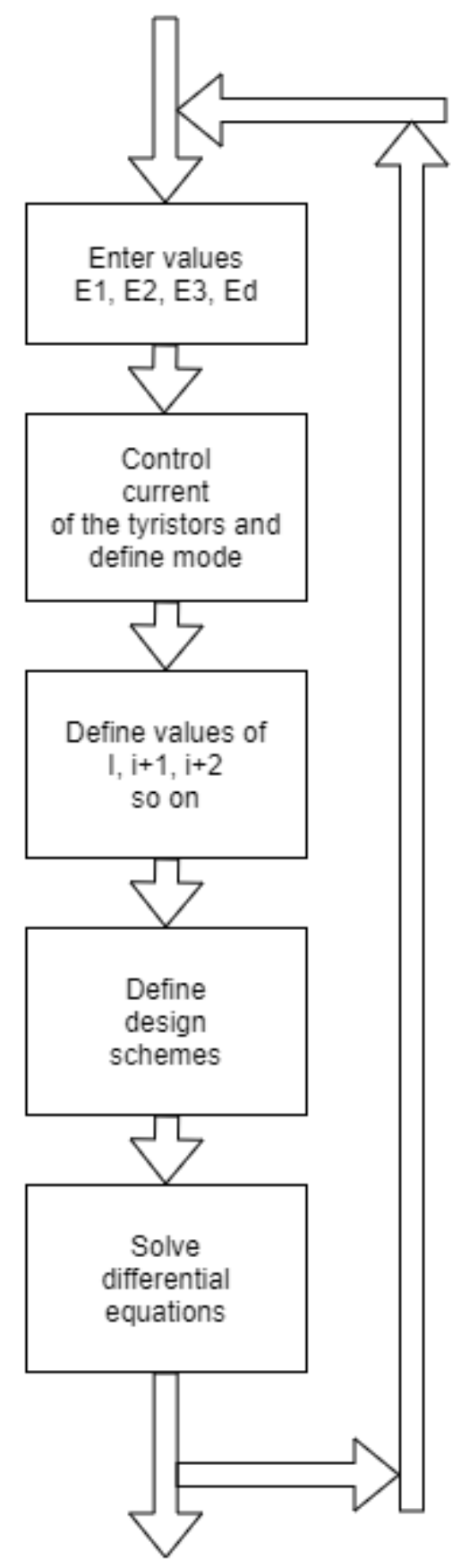

Fig. 3. A simplified diagram of the cycle algorithm within the time step of integration 


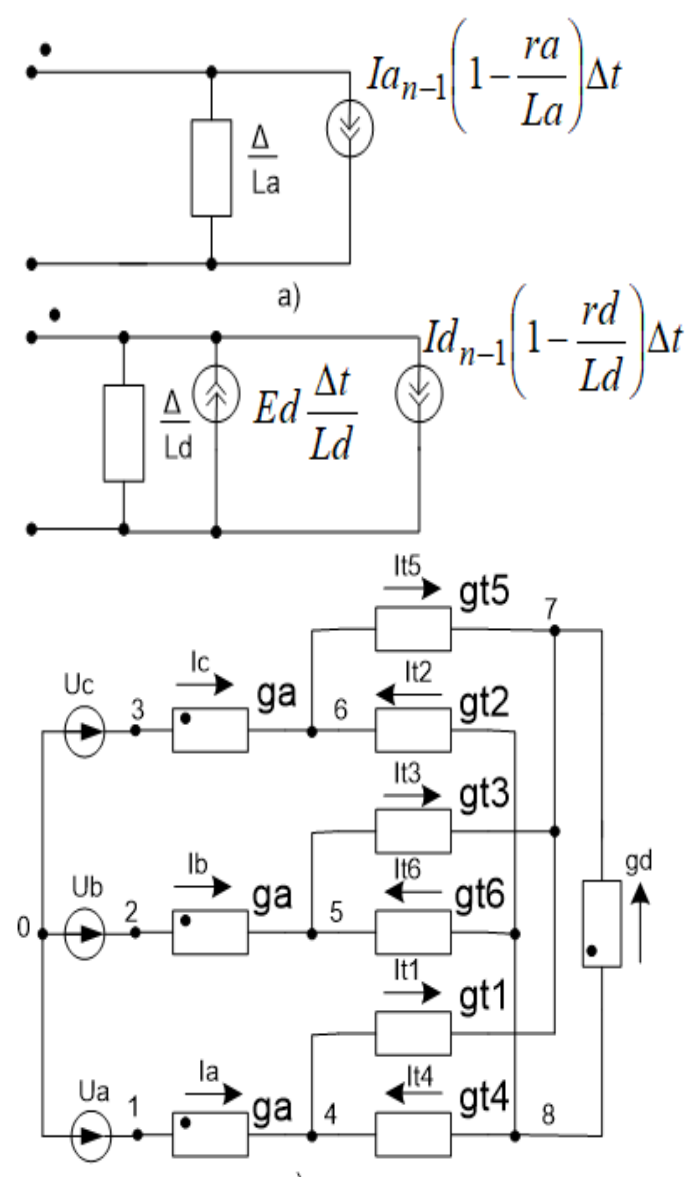

B)

Fig. 4. Discrete model of two-terminal R-L and design scheme

Therefore, further we will stop on the first way of modelling for an assessment of level of sampling of process on time.

The mathematical apparatus of the model: the solution of differential equations by the method of numerical integration of Runge-Kutta methods providing sufficient accuracy of calculations. Calculations are performed on 64-bit numbers in floating point format. Supply voltage is entered using the built-in microcomputer $\mathrm{ADC}$, and to ensure the safe voltage is fed through step-down transformers. In analog form are issued by the currents of the thyristors, anchor the motor current and the speed of rotation of the motor shaft.

Hardware mathematical model is a micro-computer family of ARM Cortex ${ }^{\mathrm{TM}}$ (A - application, R - real time, $\mathrm{M}$ - microcontroller) [10], as technology has widely spread lately. The company manufacturer of micro-computers selected from the calculation of the most fast-acting of the crystal, is presented in the line of this technology - ST Microelectronics. This microcomputer comprises peripheral means of analog-todigital converter (ADC) with a resolution of 12 bits and the digital-to-analog converter (DAC) permission. The speed of the ADC of the micro-computer at a given precision of the calculation is 5 microseconds. The implemented algorithm of calculation of parameters of electrical machines by the method of Runge-Kutta methods, when issuing the sync pulse, showed a frequency of $19.6 \mathrm{KHz}$, which corresponds to 50 microseconds per clock cycle calculation (cycle computing). This result is not final, in view of the fact that the frequency of the generator of the kernel of the micro-computer corresponded to $48 \mathrm{MHz}$ at $168 \mathrm{MHz}$ is possible for this series. Thus, the sampling frequency of the processes under control in real time close to the sampling frequency processes when using the standard virtual models of engines.

Modelling of the excitation circuit does not cause problems due to large time constants and is executed by the first method without taking into account the processes of switching thyristors. To save time, the model of the circuit runs on a separate micro-computer working with a fixed decimal point.

In the system of the stand, it is advisable to include also the load node and set various options for the loaddependent rotational speed and position of the motor shaft, to simulate the elasticity of the connecting shafts, the errors of the gears, etc [11]. For this purpose you need an additional micro-computer, in connection with a sufficiently large amount of computational tasks. All micro-computers are linked by a synchronous data transfer system that will not cause an increase in the duration of the sampling interval.

\section{Conclusions.}

Training of specialists in the field of the electric drive in higher educational institutions was generally reduced the last years to theoretical part.

Now virtual methods of research of electric drives which provide variety of tasks, rather low capital expenditure are widely used and don't demand special events for safety of performance of laboratory works.

A significant approximation of the laboratory setup to a real drive is the laboratory plant consisting of a real control system and model of the power unit (Converter installations and motor) operating without time scale.

Basic problem, arising up at creation of similar stands, it is the limited fast-acting of microcontroller for realization of model, working in real time. For the estimation of necessary fast-acting of microcontroller we consider the algorithm of work of models of transformers and engines of direct-current which is expedient for creation of the stand.

Using the proposed principle of organization of laboratory work allows the student at low capital cost: to learn how to work with real control systems, master the techniques of setting-up and definition of failure; to explore a wide range of tasks for different power levels, different nature of loads;

to investigate systems of the interconnected electric drive.

Further research should be aimed at the approximation of the mechanical part of the drive to real conditions, in particular taking into consideration the gaps in it, a nonlinear transmitting devices and etc. Modeling of gaps and nonlinear transfer devices considerably increase the volume of calculations that will demand creation of multicontroller systems and development of modeling methods for them in real time. 
It is also necessary to carefully select the element base, since microcontroller manufacturers are constantly improving their models. The main selection criterion should be the requirement to ensure sufficient productivity at a low cost.

\section{References}

1. Chornyy O. P., Lugovaya A.V., Rodkin D. Y., Sisuk V. Y., A. V. Sadovoy. Modeling of Electromechanical systems, textbook for universities, Kremenchug, (2001).

2. Esin E. K. Modeling of Electromechanical processes multimotor electric drives of mining machines. - Kemerovo: Kuzbass state technical.Univ., (1999).

3. Terekhin V. B. Simulation of electric drive systems in Simulink (MatLab 7.0.1). Tomsk: Publishing house of Tomsk Polytechnic University, (2008).

4. Shreiner R. T. Mathematical modeling of AC drives with solid state frequency converters DJVU DOC. Ekaterinburg: URO ran, (2000).

5. Patent Russian Federation N 2442995 G 01 R $31 / 34$. The stand with the electromagnetic load module for research and test of electric drives. / A.I. Nekrasov, A.V. Yefimov, A.A. Nekrasov, N. N. Serykh, V. Z. Trubnikov, (publ.12.10.2012).

6. Patent Russian Federation N 24473921, G 01 R $31 / 34$. The educational and laboratory stand for studying of electrical machines and electric drives. / Y.S. Roytburg, And, A. Sesin, Y.P. Dolgov, A.A. Prentsel, (publ. 27.01.2013).

7. D. N. Aminova, V. S. Mukhamedzhanov, V. P. Smirnov, M. R. Khalilova. A method of modeling and library of models of elements of schemes of valve converters for ATVK. The collection the Automated electric drive, Moscow, Energoatomizdat, (1983).

8. Kuzmin V.A., Moustapha G. M., Minosyan V. L. Modeling of transition process of inclusion of a tiristor on AVM. Electrotechnical industry. Converting tekhnika.(1978).

9. Nerreter V. Calculation of electric chains on the personal COMPUTER, Moscow, Energoatomizdat, (1991).

10. Y. Joseph. Kernel of Cortex-M3 of the ARM company. Full management. World Electronics series. Dodeka - XXI publishing house, Moscow, (2012).

11. Ivanushkin V.A. etc., Structural modeling of electromechanical systems and their elements/VA Ivanushkin, V. N. Sarapulov, P. Shymchak: Szczecin, (2000). 